
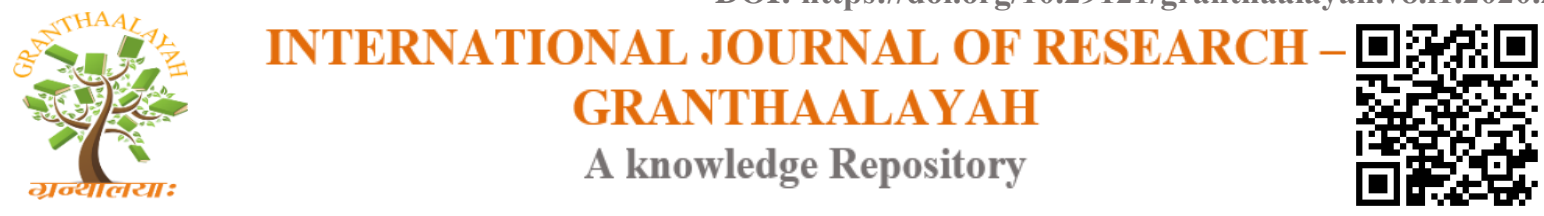

Science

\title{
THE EFFECT OF $5 \mu$ M DOSAGE OF AMLODIPINE ON NRF2 EXPRESSION IN NEURON CULTURE INDUCED BY 25 mM OF GLUCOSE
}

\author{
Shahdevi NK ${ }^{* 1}$, Nasution MTRR ${ }^{1}$, Machlusil H ${ }^{1}$, Masruroh R ${ }^{1}$ \\ ${ }^{1}$ Neurology Department, Medical Faculty of Brawijaya University, Malang, Indonesia
}

\begin{abstract}
Introduction: Hyperglycemia on neuron cell culture occurs when the cells are induced by $25 \mathrm{mM}$ of glucose. Hyperglycemia state will increase intracellular $\mathrm{Ca}^{2+}$ that leads to increased of oxidative stress in the cell. This causes the activation of antioxidant enzymes by Nrf2 protein. Amlodipine act on nerve cells through bounding with L-Type Calcium Channel (LTCC). $5 \mu \mathrm{M}$ of amlodipine has neuroprotective effect on cell culture of neuron by inhibiting cell death. Aim: The purpose of this research is to know the effect of treating amlodipine dose $5 \mu \mathrm{M}$ towards expression of the protein Nrf2 in SH-SY5Y cell culture induced by $25 \mathrm{mM}$ glucose. Methods: In this research on neuron cell culture induced $25 \mathrm{mM}$ glucose within 6 days and treated with amlodipine and without amlodipine $5 \mu \mathrm{M}$. Results: Based on research results obtained test results independent $\mathrm{t}$ test $(\mathrm{p}=$ $0,324)$ that there is no change of the Nrf2 expression significant between a given neuron cell culture with amlodipine without amlodipine. Spearman correlation test showed $(r=0.290 ; p=$ 0.361 ) that treating by amlodipine $5 \mu \mathrm{M}$ not significantly increasing Nrf2 expression. Conclusion: Based on this study it can be concluded that treating by amlodipine $5 \mu \mathrm{M}$ not give effect against Nrf2 expression on neuron cell culture induced $25 \mathrm{mM}$ glucose.
\end{abstract}

Keywords: Amlodipine; Diabetic Neuropathy; NRF2; SH-SY5Y.

Cite This Article: Shahdevi NK, Nasution MTRR, Machlusil H, and Masruroh R. (2020). "THE EFFECT OF $5 \mu \mathrm{M}$ DOSAGE OF AMLODIPINE ON NRF2 EXPRESSION IN NEURON CULTURE INDUCED BY 25 mM OF GLUCOSE." International Journal of Research - Granthaalayah, 8(1), 287-293. https://doi.org/10.29121/granthaalayah.v8.i1.2020.283.

\section{Introduction}

Hyperglycemia is a condition in which blood glucose levels increase to above normal levels. Hyperglycemia Is a sign that is obtained in diabetes mellitus (Kharroubi \& Darwish, 2015). Diabetes mellitus is a chronic metabolic disease caused by insulin produced by pancreatic beta cells which is insufficient or cannot be used effectively by the body. The distribution of diabetics in Indonesia according to riskesdas in 2013, the proportion of people over the age of 15 who suffer from diabetes mellitus in Indonesia by $6.9 \%$ or with an estimated number of 12 million people. 
This number increased compared to 2007 which stated that people over the age of 15 who had diabetes millitus in Indonesia were 5.7\% (RI, 2014). This state of diabetes can cause various kinds of complications. The complications of diabetes itself are divided into two namely acute and chronic complications. acute complications of diabetes consist of hypoglycemic and hyperglycemic crises, whereas chronic complications consist of macroangiopathy and microangiopathy. Diabetic macroangiopathy complications consist of coronary heart disease, peripheral vascular disease, or cerebral vascular disease such as stroke, whereas complications of diabetes microangiopathy consist of retinopathy, nephropathy and neuropathy (Nurlaela et al., 2019). Diabetic neuropathy treatment still requires a lot of development. Although there are enough pharmacological approaches to treat diabetic neuropathy, but treatments that really target the root cause of diabetic neuropathy besides strict control of blood sugar still need further understanding (Kharroubi \& Darwish, 2015). So that potential therapeutic targets must continue to be developed and in the future therapeutic agents working at the level of mitochondrial metabolic control will improve DSPN treatment (Singh et al., 2014). In hyperglycemic neuron cell culture occurs when the cells are given glucose induction exceeds $25 \mathrm{mM}$ (Shi \& Liu, 2006). In cells experiencing hyperglycemia an increase in ROS precursors can occur so that oxidative stress also increases. This increase in ROS can occur due to mitochondrial dysfunction through the disruption of the $\mathrm{Ca}^{2+}$ ion homeostasis process and the disruption of the $\mathrm{Ca}^{2+}$ ion buffer system in the mitochondria by limiting the amount of ATP dependent transport. This results in a steady increase in intracellular $\mathrm{Ca}^{2+}$ ion concentration, an increase in low and high $\mathrm{Ca}^{2+}$ flow, and a decrease in the amplitude of the $\mathrm{Ca}^{2+}$ ion depolarization induction signal (Verkhratsky \& Fernyhough, 2014).

An increase in uncontrolled $\mathrm{Ca}^{2+}$ ions and the resulting ER stress results in an increase in oxidative stress in the cell. This results in the activation of the Nrf2 protein which functions as a transcription factor for the expression of antioxidant enzymes. Transcription protein Nrf2 will express SOD (superoxide dismutase) as an antioxidant agent. However, when there is an increase in oxidative stress, it causes a decrease in the quality of the activation of antioxidant enzymes in capturing free radicals. One of these enzymes is SOD (Akki et al., 2018). This can cause an increase in ROS, so that it can increase the occurrence of apoptosis and damage to neuronal cells resulting in neuropathy (Rochette et al.,2014). Nrf2 is a protein that functions to protect cells from apoptosis by increasing antioxidant proteins in response to increased oxidative stress. Under normal conditions (non-stress) Nrf2 has a low concentration in the cell and is retained in the cytoplasm, whereas when there is an increase in oxidative stress the concentration of Nrf2 in the cell will increase and Nrf2 will undergo translocation into the cell nucleus to regulate gene expression involved in antioxidant responses (Rochette et al., 2014). Amlodipine is a drug from the calcium channel blocker class. Amlodipine works by inhibiting the inflow of transmembrane from calcium to smooth muscle cells (Fares et al., 2016). Amlodipine can also work on nerve cells by binding to the L-Type Calcium Channel (LTCC) (Bhardwaj et al., 2015).

\section{Materials and Methods}

\subsection{Research Design}

This study uses a pure experimental research design (true experimental design) at the Central Laboratory of Biological Sciences (LSIH) Universitas Brawijaya in vitro on neuron cell culture. 


\subsection{Research Samples}

The sample of this study used SH-SY5Y culture cells that met the inclusion and exclusion criteria, with a total sample of 12. Samples were divided into 2 groups namely, given amlodipine $5 \mu \mathrm{M}$ ( $\mathrm{n}$ $=6)$ and without amlodipine $(n=6)$.

\subsection{Nrf2 Expression Examination}

Examination of Nrf2 expression using antibodies by immunoflorescence. Nrf2 observations were carried out using confocal laser screening microscopy (CLSM). Nrf2 calculation is done with Olympus Fluoview Ver4.2a with an au unit (aberrant unit).

\section{Results}

Research on the effect of amlodipine on Nrf2 protein expression in SH-SY5Y neuron culture with chronic hyperglycemic models has been carried out. From week 1 to week 3, the process and growth of cells from SH-SY5Y neuron culture cells were carried out to a minimum of $80 \%$ confluent cells. After confluent cells of at least $80 \%$, then harvest cells and subcultures are carried out until at least $80 \%$ of cells become confluent again. After the cells are ready, then platting will be done on well 24 by first inserting 24 slips of cover into the well. Then it was observed for up to 3 days until the number of cells was considered sufficient to intervene with glucose. Glucose induction was given to SH-SY5Y cells with a concentration of $25 \mathrm{mM}$ for 6 days. Then the amlodipine intervention was carried out at a dose of $5000 \mathrm{~nm}$ and waited for up to 30 minutes. After that, the label Nrf2 assay was given to the SH-SY5Y neuron culture cell and the Nrf2 protein expression was checked using a CLSM (Confocal Laser Scanning Microscopy) tool.

Normality Test with the Shapiro-Wilk method results obtained $\mathrm{p}=0.536$ which shows that the distribution of data is normal. Furthermore, the homogeneity test results obtained $p=0.076$ which can be concluded that the data is homogeneous. After finding normal and homgenous data, a comparative test with independent $\mathrm{T}$ test was performed. Reached $\mathrm{p}=0.324$. These results indicate that administration of amlodipine has No. effect on Nrf2 expression. The Spearman correlation test shows a correlation value of 0.290 and a significance value of $p<0.360$ which means there is No. significant correlation $(\mathrm{p}<0.05)$ between administration of amlodipine and Nrf 2 expression. The direction of the correlation is positive, which means that administration of amlodipine increases Nrf2 expression with a weak relationship.

Table 1: Nrf2 mean result

\begin{tabular}{|r|r|r|}
\hline Treatment Group & Mean & Standard error \\
\hline Glucose $25 \mathrm{mM}$ without Amlodipine & 8.3833 & 0.68456 \\
\hline Glucose $25 \mathrm{mM}+$ Amlodipine $5 \mu \mathrm{M}$ & 9.2072 & 0.40380 \\
\hline
\end{tabular}




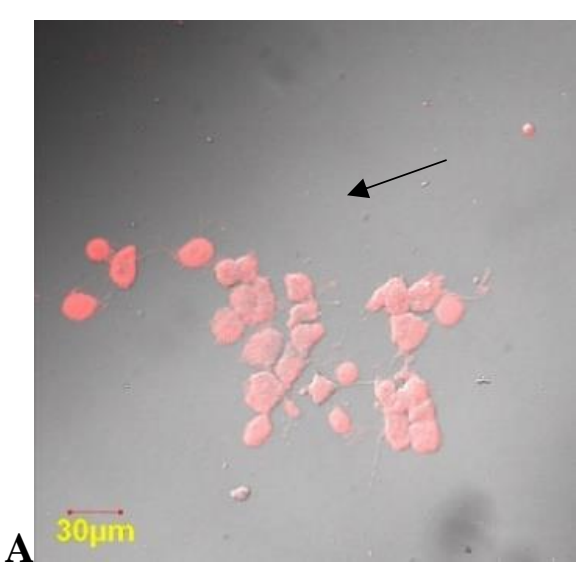

Figure 1: Nrf2 expression in neuron culture by treating hyperglycemia $(25 \mathrm{mM})$. Figures $\mathrm{A}$ without the administration of amlodipine, B are treated with $5 \mu \mathrm{M}$ amlodipine. Arrows indicate Nrf2 expression in SH-SY5Y neuron cell culture. (Culture day 6, Nrf2 red rhodamine, DIC, superimpose, 400x magnification).

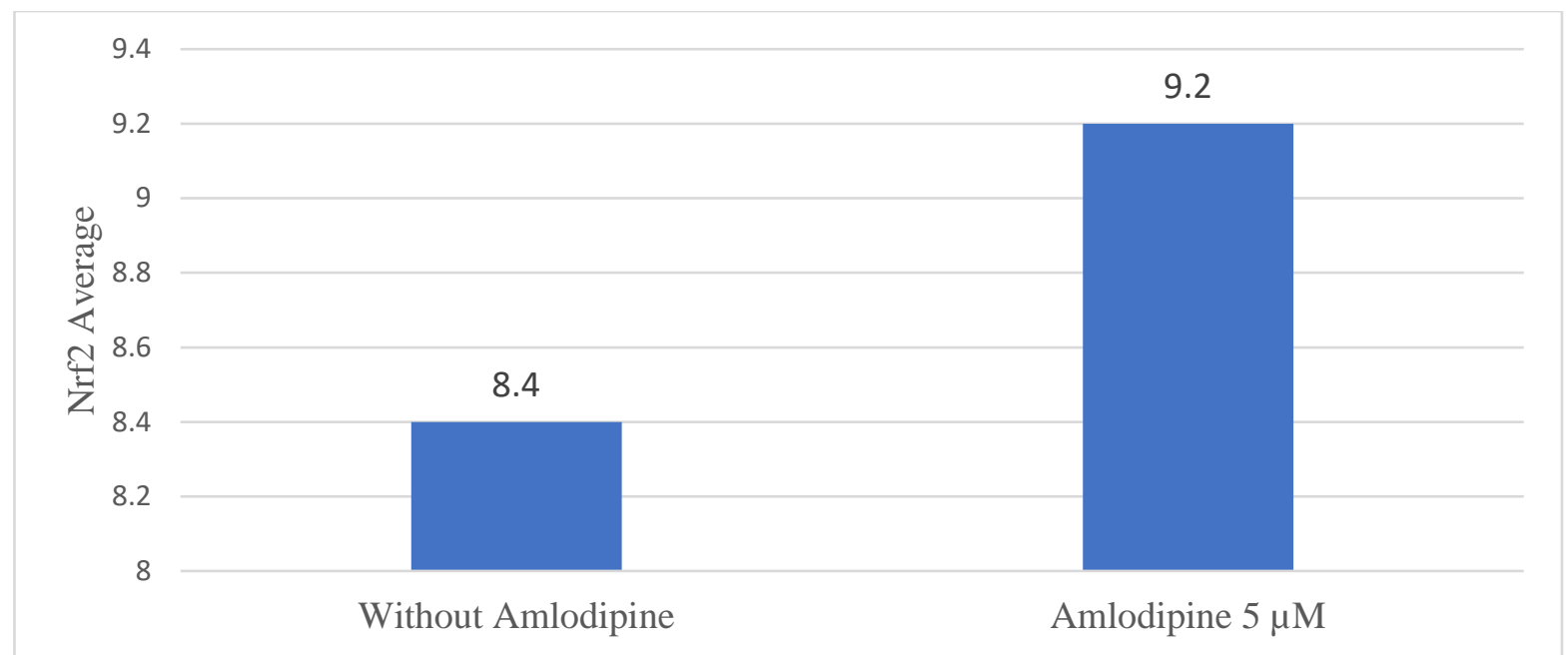

Figure 2: Average histogram of Nrf2 expression in SH-SY5Y neuron culture with amlodipine 5 $\mu \mathrm{M}$ intervention and without amlodipine.

\section{Discussions}

In this study the correlation test results between cells that were not given amlodipine and those who were given amlodipin $5 \mu \mathrm{m}$ were positive $(\mathrm{r}=0.290)$. This means that administration of amlodipine can increase Nrf2 expression even with a weak correlation. In the calculation with the formula d-type effect size also obtained a d value of 1.61 which means that giving amlodipine gives a very large effect on Nrf2 expression. This can occur due to various factors that can activate Nrf2. In additional studies conducted in this study using SH-SY5Y cell culture induced by $25 \mathrm{mM}$ glucose and $100 \mathrm{nM}$ amlodipine showed Nrf2 translocation to the nucleus is characterized by Nrf2 that gather in the middle. In a study conducted by Chung in 2016 on unilateral ureteral obstructioninduced renal fibrosis which showed that T-type CCB can reduce unilateral ureteral obstructioninduced renal fibrosis by activating Nrf2 and increasing regulation of the enzymes and antioxidant genes that are regulated. This is because T-type CCB has been shown to significantly inhibit NF- 
$\mathrm{kb}$ in mesangial cells (Chung et al., 2016). In another study conducted by Da hyun in 2017 regarding the effect of acetaminophen cytotoxicity on liver cells, it was found that verapamil, a non-dihydropyridin CCB that works on L-Type calcium channel and T-type calcium channel, can prevent the effects of acetaminophen cytotoxicity with activate Nrf2. Activation of Nrf2 by verapamil is due to the ability of verapamil to promote p62 protein which is a specific protein that interacts with Keap1 and competitively inhibits interactions between Nrf2 and Keap1 so that NRF2 stabilization occurs and increased expression (Gurkoff et al., 2013; Lee et al., 2017). In a study on acute mountain sickness (AMS), it was found that amlodipine can increase Nrf2. The study was carried out using AREc23 cells, which are breast cancer cell lines, which are exposed to high altitude using hypobaric chambers and then given amlodipine showed that amlodipine can increase Nrf2 as a side target of PI3K/Akt pathway activation (Lisk et al., 2013). The PI3K/Akt pathway is a pathway that has an important role in the regulation of cell function that is very fundamental, namely proliferation and angiogenesis. Activation of the Akt pathway can also make cells become resistant to apoptotic signals (Divolis et al., 2016).

In the independent $\mathrm{T}$ test, it was found that the mean Nrf2 expression was not significantly different between the $5 \mu \mathrm{M}$ amlodipine cell groups and the cell groups that were not given amlodipine. In the correlation test even though a positive correlation coefficient $(r=0.290)$ was obtained, but the $\mathrm{p}$ value indicates the results of this study were not significant. This means that the administration of $5 \mu \mathrm{M}$ amlodipine has no effect on SH-SY5Y cells induced by $25 \mathrm{mM}$ glucose. This is expected to occur due to other factors that can also interact with $\mathrm{Nrf2}$. One of which is regulated by $\mathrm{Ca}^{2+}$ is IQGAP1. IQGAP1 is a scaffolding protein that binds to various molecules in the cell. By interacting with the target protein IQGAP1 protein in several cellular functions including $\mathrm{Ca}^{2+} /$ calmodulin signaling, cell architecture, CDC42 signaling and rac, and $\beta$-catenin-mediated transcription (Briggs \& Sacks, 2003). In a study conducted by Kim in 2013 stated that IQGAP1 can interact with Nrf2 and cause stabilization of Nrf2 and can also increase translocation, activation and expression of Nrf2. The interaction between IQGAP1 and its protein targets including $\mathrm{Nrf} 2$ can be modulated by calmodulin and its relationship with $\mathrm{Ca}^{2+}$. Increased intracellular $\mathrm{Ca}^{2+}$ which can cause conformational changes from calmodulin and followed by its binding to the target protein. With this it can be concluded that an increase in $\mathrm{Ca}^{2+}$ can increase calcium binding protein with IQGAP1 and increase the activation of Nrf2 bound to IQGAP1 (Kim et al., 2013). The inhibition of $\mathrm{Ca}^{2+}$ by amlodipine can inhibit the above process so that the activation of Nrf2 also becomes inhibited. Suggestions from this study are the need for further studies with several doses of amlodipine to compare the optimal dose to increase the expression of Nrf2 protein and other factors that affect Nrf2 expression such as, SOD, Nrf2 translocation, NFkb, PI3K/Akt, and IQGAP1 (Kim et al., 2013).

\section{Conclusions}

Based on the results of the study the effect of giving $5 \mathrm{mg} \mu \mathrm{M}$ amlodipine to Nrf2 protein in $\mathrm{SH}-$ SY5Y neuron-induced cell culture of glucose $25 \mathrm{mM}$, it can be concluded that the administration of $5 \mu \mathrm{m}$ amlodipine in SH-SY5Y neuron cell culture induced by chronic hyperglycemia (glucose $25 \mathrm{mM}$ ), it can be concluded that administration of $5 \mu \mathrm{m}$ amlodipine in SH-SY5Y neuron cell culture induced by chronic hyperglycemia (glucose $25 \mathrm{mM}$ ) has not been concluded. can increase $\mathrm{Nrf} 2$ protein expression, there is no statistically significant relationship between amlodipine dose 
of $5 \mu \mathrm{M}$ to increase Nrf2 protein expression, there is no difference in Nrf2 expression between neuron cell cultures given amlodipine.

\section{Acknowledgement}

This research was carried out with the financial support of BPPM (Agency for Research and Community Service) Faculty of Medicine, Brawijaya University, Malang, Indonesia.

\section{References}

[1] Akki, R., Siracusa, R., Morabito, R., Remigante, A., Campolo, M., Errami, M., La Spada, G., Cuzzocrea, S., \& Marino, A. Neuronal-like differentiated SH-SY5Y cells adaptation to a mild and transient H 2 O 2 -induced oxidative stress. Cell Biochemistry and Function, March 2018, 36(2), 56-64.

[2] Bhardwaj, V., Nehra, S., Bansal, A., Saxena, S., Singh, M., \& Saraswat, D. The effect of amlodipine in ameliorating the hypobaric hypoxia induced neuronal damages and dysfunction. International Journal of Pharmaceutical Sciences and Research, 2015, 6(7), 2770-80.

[3] Briggs, M. W., \& Sacks, D. B. IQGAP proteins are integral components of cytoskeletal regulation. EMBO Reports, June 2003, 4(6), 571-574.

[4] Chung, S., Kim, S., Kim, M., Koh, E. S., Yoon, H. E., Kim, H.-S., Park, C. W., Chang, Y. S., \& Shin, S. J. T-type calcium channel blocker attenuates unilateral ureteral obstruction-induced renal interstitial fibrosis by activating the Nrf2 antioxidant pathway. American Journal of Translational Research, 2016, 8(11), 4574-4585.

[5] Divolis, G., Mavroeidi, P., Mavrofrydi, O., \& Papazafiri, P. Differential effects of calcium on PI3KAkt and HIF-1 $\alpha$ survival pathways. Cell Biology and Toxicology, October 25, 2016, 32(5), 437449.

[6] Fares, H., DiNicolantonio, J. J., O’Keefe, J. H., \& Lavie, C. J. Amlodipine in hypertension: a firstline agent with efficacy for improving blood pressure and patient outcomes. Open Heart, September 28, 2016, 3(2), e000473.

[7] Gurkoff, G., Shahlaie, K., Lyeth, B., \& Berman, R. Voltage-Gated Calcium Channel Antagonists and Traumatic Brain Injury. Pharmaceuticals, June 26, 2013, 6(7), 788-812.

[8] Kharroubi, A. T., \& Darwish, H. M. Diabetes mellitus: The epidemic of the century. World Journal of Diabetes, June 25, 2015, 6(6), 850-867.

[9] Kim, J.-H., Xu, E. Y., Sacks, D. B., Lee, J., Shu, L., Xia, B., \& Kong, A.-N. T. Identification and Functional Studies of a New Nrf2 Partner IQGAP1: A Critical Role in the Stability and Transactivation of Nrf2. Antioxidants \& Redox Signaling, July 10, 2013, 19(2), 89-101.

[10] Lee, D. H., Park, J. S., Lee, Y. S., Sung, S. H., Lee, Y.-H., \& Bae, S. H. The hypertension drug, verapamil, activates Nrf2 by promoting p62-dependent autophagic Keap1 degradation and prevents acetaminophen-induced cytotoxicity. BMB Reports, February 2017, 50(2), 91-96.

[11] Lisk, C., McCord, J., Bose, S., Sullivan, T., Loomis, Z., Nozik-Grayck, E., Schroeder, T., Hamilton, K., \& Irwin, D. C. Nrf2 activation: A potential strategy for the prevention of acute mountain sickness. Free Radical Biology and Medicine, October 2013, 63, 264-273.

[12] Nurlaela, S., Kurniawan, S. N., \& Husna, M. Electroneuromyography Examination Of Diabetic Polyneuropathy Patients. MNJ (Malang Neurology Journal), January 1, 2019, 5(1), 1-4.

[13] RI, K. K. InfoDATIN: Situasi dan Analisi Diabetes. Kementrian Kesehatan RI, 2014, 1-2.

[14] Rochette, L., Zeller, M., Cottin, Y., \& Vergely, C. Diabetes, oxidative stress and therapeutic strategies. Biochimica et Biophysica Acta (BBA) - General Subjects, September 2014, 1840(9), 2709-2729. 
[15] Shi, H., \& Liu, K. J. Effects of glucose concentration on redox status in rat primary cortical neurons under hypoxia. Neuroscience Letters, December 13, 2006, 410(1), 57-61.

[16] Singh, R., Kishore, L., \& Kaur, N. Diabetic peripheral neuropathy: Current perspective and future directions. Pharmacological Research, February 2014, 80, 21-35.

[17] Verkhratsky, A., \& Fernyhough, P. Calcium signalling in sensory neurones and peripheral glia in the context of diabetic neuropathies. Cell Calcium, November 2014, 56(5), 362-371.

*Corresponding author.

E-mail address: shahdevinandar@y yhoo.com 